\title{
Tramas publicitarias de las pymes del sector textil
}

Salvador Carrillo Checa y Luis Velezmoro Morales (Universidad de Lima)

Recibido: 03/10/09

Aceptado: 15/11/09

RESUMEN: El presente estudio trata de las estrategias de comunicación publicitaria que aplican las pymes del sector confecciones de Lima metropolitana para comercializar sus productos y servicios. Aun cuando las pymes actúan en diversos sectores, se tomó como base de estudio el sector de comercialización de productos textiles por ser el más relevante y porque es el que más invierte en publicidad para comunicarse con el mercado.

Palabras clave: Publicidad / pymes (pequeña y mediana empresa) / inversión en medios / estrategia creativa

\section{Advertising plots for small and medium sized companies of the textile sector}

SUMMARY: This study is about the advertising communication strategies applied by the Lima's clothing industry small and medium enterprises (SME) in order to commercialize their services and products. Even though the SME perform in many areas, the textile products' marketing area is set as the base of this study because of it's relevance and also because this area is the one with the biggest investment in advertising in order to communicate with the market.

Keywords: Advertising / SME / media investment / creative strategy 


\section{Introducción}

T as pymes han creado y recreado Luna serie de estrategias publicitarias que escapan a toda convención, desde el perifoneo en circuitos internos de radio y la distribución de volantes y tarjetas en los mismos puntos de venta, hasta el uso de la televisión a través de anuncios económicos y product placement o colocación de su marca en programas dirigidos a sus consumidores. La curiosidad por conocer más detalladamente este tipo de publicidad y la necesidad de capacitación para su eficacia comunicativa, fueron el punto de partida de esta investigación que constó de dos etapas: la primera, que consistió en un estudio cualitativo para el cual se realizaron entrevistas en profundidad y focus group con propietarios de pymes, para conocer y analizar sus estrategias publicitarias. La información aquí obtenida sirvió de base para diseñar y ejecutar la segunda etapa del proyecto, consistente en un estudio cuantitativo sobre el mismo tema.

Los resultados del trabajo reflejaron las tramas publicitarias (estrategias) de las pymes, las cuales, de algún modo, replican a escala a las grandes empresas para lograr sus objetivos, y ponen de manifiesto cómo han desarrollado sus propios soportes; por ejemplo, la "janta" (cartoncitos/etiquetas publicitarias adheridas a las prendas, cuyo nombre proviene del inglés hang), utilizada como medio publicitario para llegar a sus consumidores.
Una característica típica de las pymes es que, en sus inicios, estaban conformadas por grupos familiares que trabajaban repartiéndose las funciones de acuerdo con las habilidades de sus componentes. Al respecto, Andriani afirma:

Este tipo de organización es el que predomina en el mundo. Significa que uno abrió un negocio y aprovechó su expansión para incluir familiares, sea en la gestión o en la operación normal, hasta que muchos de ellos llegaron a ser socios, por naturaleza, de la iniciativa al utilizar el capital de la familia.

Muchas de estas empresas consiguen éxito con esta administración, porque su líder logra conciliar el interés de las personas con los de la organización, gestionando un negocio de forma profesional y exigiendo a cada uno que cumpla con su responsabilidad (Andriani, Biasca y Rodríguez 2003: 170).

En el Perú, la denominada "Ley General de la Pequeña y Microempresa" las ha definido, en su artículo 2, de la siguiente forma:

Entiéndase por Pequeña y Microempresa a aquella unidad económica que opera una persona natural o jurídica, bajo cualquier forma de organización o gestión empresarial, que desarrolla actividades de extracción, transformación, producción y comercialización de bienes o prestación de servicios, dentro de los parámetros establecidos en el Reglamento de la presente Ley (Ley 27268). 
Todas las empresas, al margen de su tamaño, requieren de un plan estratégico para comercializar sus productos. Philip Kotler (1998: 38), autoridad mundial en márketing, plantea lo siguiente:

La planeación estratégica es el proceso de desarrollar y mantener un ajuste estratégico entre las metas y capacidades de la organización y sus oportunidades de mercadotecnia cambiantes. Consiste en el desarrollo de una misión clara de la compañía, de objetivos de apoyo de la compañía, de una cartera de negocios sólida y de la coordinación de las estrategias funcionales.

Una de las aristas más relevantes de las estrategias de comunicación de las empresas es la publicidad. Para William Stanton (2000: 482), de la Universidad de Colorado, la publicidad es:

Una comunicación no personal, pagada por un patrocinador claramente identificado, que promueve ideas, organizaciones o productos. Los puntos de venta más habituales para los anuncios son los medios de transmisión por televisión y radio y los impresos (diarios y revistas). Sin embargo, hay muchos otros medios publicitarios, desde los espectaculares a las playeras impresas $y$, en fechas más recientes, el Internet.

Una empresa, por más pequeña que sea, necesita un plan de comunicación publicitaria que incluya estrategias de medios y creativa. Esta últi- ma incluye, a su vez, la promesa de que se ofrecerá al consumidor el mejor producto y se le dará una razón de por qué, mediante una enunciación que refuerce directamente la promesa, basada de preferencia en un hecho y nunca en un catálogo de las características del producto.

Otto Kleppner's (1988: 33) destaca la importancia de la publicidad detallista como una de las formas más comunes empleadas por las pymes:

La publicidad detallista no sólo intenta vender un producto, sino que además anima al comprador a adquirirlo en una tienda específica. El anunciante nacional es feliz de vender sus productos en cualquier ubicación. La publicidad detallista debe darle una razón al consumidor para que compre en una sola tienda. Por esto, la publicidad detallista es muy específica en términos de beneficios al consumidor. Tradicionalmente, recalca el precio, especialmente de artículos de venta. También da a conocer el horario de la tienda, las políticas de crédito, y cualquier otra información que distinga una tienda de las otras que venden la misma mercancía.

Luis Bassat (1999: 49) manifiesta que la ejecución creativa debe persuadir y distinguir a través de la publicidad, definiendo su rol de la siguiente manera:

El papel de la publicidad sigue siendo informar y convencer, pero también seducir y persuadir. 
Las técnicas han evolucionado, y la necesidad y conveniencia de la creatividad en la ejecución publicitaria es hoy ya incuestionable. Para que esta creatividad sea verdaderamente eficiente necesitamos que esté al servicio del producto y su estrategia, de una idea vendedora; que comunique y que sea atractiva, que no aburra.

La comunicación es un elemento esencial en las estrategias comerciales de las empresas; por ello, en la última década ha tenido más protagonismo la combinación o integración de estas para llegar al consumidor final. Como complemento de la publicidad tradicional, que usa medios ATL (above the line), como televisión, radio, prensa, etcétera, las empresas han encontrado otras estrategias de medios alternativos o BTL (below the line) y acciones para captar o mantener clientes. Entre las más populares podemos mencionar:

- Publicidad gratuita del producto: Dar a conocer un producto o servicio específico de manera gratuita (en nuestro medio se le conoce como "publicherry").

- Comunicación corporativa: Creación de mensajes internos y externos para promover una imagen positiva de la compañía o institución.

- Asuntos públicos: Establecimiento y mantenimiento de relaciones con la comunidad nacional o local.

- Cabildeo (lobbying): Influencia sobre legisladores y funcionarios del gobierno para promover o impedir iniciativas de legislación y reglamentos.

- Relaciones con empleados e inversionistas: Mantenimiento de relaciones positivas con los empleados, accionistas y otras personas en la comunidad financiera.

- Manejo de crisis: Respuesta a una publicidad desfavorable o un acontecimiento negativo.

- Colocación del producto (product placement): En eventos especiales, como películas o programas de televisión.

- Relaciones públicas: Para evaluar actitudes del público, identificar temas que generan preocupación social y desarrollar programas para captar la comprensión y aceptación de la gente.

\section{Inversión publicitaria en el sector confecciones}

Previamente a la investigación de la gestión publicitaria en los confeccionistas de las pymes, fue necesario conocer el volumen de las inversiones publicitarias en este rubro. Con la información de Media Check S.A para el período 2005, se pudo observar que en el sector vestimenta las inversiones publicitarias se presentaron principalmente en la categoría de prendas de vestir en general, que es donde se ubica el mayor volumen publicitario; le siguen los pantalones jeans y, en menor 
medida, las prendas dirigidas a hombres, mujeres y niños. Con volúmenes de inversión más pequeños, se encuentran las categorías especializadas, como la ropa interior y de baño.

El sector vestimenta en su conjunto presenta una inversión de US\$6,9 millones, cifra medida a tarifa impresa. Deduciendo los altos descuentos que se dan en nuestro medio, el monto real de la inversión estaría aproximadamente en US\$1,5 millones, lo cual representa el 0,8\% del total de la inversión publicitaria en los medios masivos de Lima.

Las grandes y medianas participan con el 89,2\% del total de la inversión, mientras que las pequeñas tienen una participación del 10,8\% en la compra de espacios publicitarios en medios masivos.

Los pantalones jeans son los más publicitados, por ser la prenda más popular y por lo generalizado de su uso en todos los niveles socioeconómicos de la población. Por tal motivo, tanto las marcas grandes como las pequeñas utilizan de preferencia los medios masivos de mayor penetración, como la televisión y la radio.

Las marcas de mayores recursos invierten más en televisión y efectúan publicidad continua durante el año, mientras que las pequeñas utilizan la televisión para campañas cortas y puntuales en fechas como el Día de la Madre, del Padre y en Navidad, periodos que se caracterizan por un incremento importante en las ventas.
La línea de confecciones femeninas invierte 290,8 mil dólares al año, destacando la marca Yol, orientada al nivel bajo ascendente, con alta presencia en las galerías de Gamarra y en el Centro de Lima, cuyo presupuesto publicitario está orientado a la televisión $\mathrm{y}$, en menor medida, a la radio. Las demás marcas, incluidas las pequeñas, presentan bajas inversiones, siendo las revistas el medio de publicidad preferido.

Otras líneas, como la confección para niños, la ropa interior femenina y masculina y los trajes de baño, también invierten poco en publicidad y lo hacen preferentemente en revistas. Ello sucede, por ejemplo, en los casos de trajes de baño y ropa interior femenina, que buscan a su grupo objetivo en publicaciones especializadas, ya que, de este modo, ganan una mejor imagen para su producto. Las marcas Angelo's Kid, en ropa de niños, y Lancaster, en ropa interior masculina, presentan inversiones de exiguo presupuesto en televisión con campañas estacionales y baja frecuencia de avisos.

\section{Estudio cualitativo sobre las estrategias de comunicación publicitaria aplicadas por las pymes del sector confecciones de Lima metropolitana}

Como ha quedado señalado, el objetivo general de la investigación implica conocer las prácticas publicitarias en 
las pymes del sector confecciones de Lima metropolitana. Para ello será preciso, como metas específicas, evaluar el nivel de conocimiento y aplicación de sus alternativas publicitarias y promocionales más frecuentes.

Para su logro fue necesario aplicar, en una primera fase, el método cualitativo, las técnicas de focus group y entrevistas en profundidad. En lo que respecta a los pequeños confeccionistas, se convino en emplear las entrevistas en profundidad como técnica cualitativa para recoger la información prevista, dado que en la etapa de reclutamiento se observó una gran dificultad para coincidir con sus agendas. Este no fue el caso de los medianos confeccionistas (como los participantes fueron los encargados de la publicidad o márketing, y ellos cuentan con horarios fijos de trabajo, pudieron aplicarse los focus group).

Se encontraron tres segmentos de pymes: las que cuentan con marca y hacen publicidad, las que teniendo marca no hacen publicidad y las que no tienen marca y no hacen publicidad.

Respondiendo a nuestro principal objetivo, la investigación se centró en las pymes que sí hacen publicidad, porque las que tienen marca y no hacen publicidad están más enfocadas a la producción y comercialización de telas. Las que no tienen marca y no hacen publicidad se dedican, más bien, a dar servicios de confección a terceros, aunque también buscan cre- cer y capacitarse con el fin de acceder a mayores mercados.

Los segmentos de pequeños empresarios confeccionistas que no realizan publicidad pero cuentan con marca, no invierten en publicidad porque no disponen de capital para ello $y$, además, por desconocimiento de las alternativas de comunicación acordes a su sector. Algunos de ellos hicieron publicidad limitada en la "radio interna" de la galería, en calendarios, en bolsas y en las Páginas Amarillas, pero manifestaron no haber tenido un retorno positivo en sus ventas.

La mayoría de confeccionistas que realizan publicidad señalan encontrarse satisfechos con esta actividad porque tienen experiencia en el rubro, y la consideran relevante debido a que, merced a ella, han incrementado sus ventas, han ganado mayor participación en el mercado, $y$ han fortalecido su imagen y forjado su marca en el consumidor.

Las pymes realizan publicidad también, aunque en menor grado, mediante promociones llevadas a cabo como auspiciadoras de otros eventos, así como también mediante su participación en desfiles de modas, ferias nacionales e internacionales y ruedas de negocios promovidas por Prompex.

Las pymes de confecciones que cuentan con marca suelen efectuar canjes publicitarios con emisoras de radio y canales de televisión, publicitan en revistas (como, por ejemplo, la del emporio de Gamarra), tienen una 
página web y realizan campañas promocionales en los días de la Madre, del Padre y Navidad, entre otras fechas. Los confeccionistas que cuentan con locales en Gamarra utilizan volantes y "janta", que se colocan en la misma prenda, con el fin de proyectarse a otros mercados.

También utilizan carteles en sus establecimientos comerciales de venta al público; exhiben sus prendas en maniquíes; emplean "jaladores" ubicados a la entrada de las galerías, que ofrecen los productos y conducen a los clientes al local o stand promocionado; entregan tarjetas de presentación o volantes donde incluyen información diversa sobre los productos comercializados, así como planos de ubicación, tanto de la galería como del local, con la finalidad de facilitar la llegada del cliente al establecimiento. Algunos pequeños confeccionistas auspician eventos, hacen relaciones públicas con gremios y ONG, y participan en ruedas de negocios y ferias nacionales e internacionales.

En el caso de los medianos confeccionistas la inversión publicitaria está consignada en sus planes operativos anuales. Son empresas que cuentan con profesionales especializados en márketing y publicidad, que los conciben como una inversión que revierte no solo en las ventas sino que también refuerza su imagen de marca. Este segmento realiza básicamente publicidad televisiva, e incluso algunos medianos confeccionistas cuentan con agencias de publicidad para la creatividad y centrales de medios para planificar su inversión. También han desarrollado websites para tener contacto con otros mercados del mundo.

Resumiendo, los medianos empresarios generalmente:

- Utilizan publicidad televisiva para llegar a mayor cantidad de público.

- Utilizan publicidad gráfica para compartir gastos con las tiendas por departamentos donde comercializan sus productos.

- Contratan anuncios en las Páginas Amarillas, porque existen clientes que usan este medio.

- Ofertan y rematan productos, porque ello les permite vender los saldos de exportación y los saldos en general.

- Realizan canjes televisivos donde tienen "publicherrys" (publicidad gratuita o publicity).También hacen uso de estrategias de product placement (ubicar la marca en novelas, programas o series televisivas), e incluso visten a los artistas o presentadores de programas o espacios auspiciados.

- Realizan relaciones públicas con instituciones y autoridades para promocionar sus marcas.

- Participan esporádicamente en desfiles de moda.

- Efectúan donaciones con fines tributarios más que solidarios. 
Por su parte, los pequeños confeccionistas utilizan principalmente:

- Etiquetas ("jantas") de la marca, donde incluyen el teléfono de la empresa, porque así acceden a diferentes sectores y lugares.

- Letreros, pancartas y tarjetas personales, porque son alternativas más económicas.

- Tarjetas personales con información publicitaria adicional.

- Radio de la galería, porque convoca clientes potenciales y se hacen conocidos.

- Participan en eventos como polladas, desfiles, etcétera.

Entre los pequeños confeccionistas el contenido de la publicidad y los medios son elegidos generalmente por el dueño de la empresa o sus familiares, basándose, para el caso del contenido del mensaje, en los siguientes criterios: que sea escueto, llamativo, bonito, estético y agradable a la vista. Excepcionalmente, contratan un creativo o publicista, y en esos casos exigen que la publicidad sea "impresionante", "sensacional", "exclusiva" y se diferencie de la competencia ubicada en su entorno más próximo.

Los medianos confeccionistas intervienen para decidir las alternativas presentadas ya sea por su agencia o su departamento interno de publicidad, y en el caso del presupuesto publicitario asignan un monto no mayor del $2 \%$ de sus ventas.
Con respecto al nombre de las marcas se observa que estas han sido creadas por los mismos propietarios o por algún familiar cercano, como es el caso de Pieer's, Roys, Fillipo Alpi, Adams, Él, John Holden, entre otras. Es muy frecuente el uso de nombres anglosajones en sus marcas, debido, tal vez, a deseos aspiracionales que manifiestan muchos consumidores peruanos.

\section{Estudio cuantitativo sobre las estrategias de comunicación publicitaria aplicadas por las pymes del sector confecciones de Lima metropolitana}

El estudio cualitativo ayudó a identificar los objetivos específicos para conocer y cuantificar las prácticas publicitarias de las pymes del sector de confecciones: tipos de actividades publicitarias, grado de profesionalismo en la gestión publicitaria y percepciones sobre la importancia e influencia de la publicidad.

La técnica empleada consistió en la entrevista personal al ejecutivo encargado de la publicidad de la pyme, a quien se aplicó un cuestionario preestructurado y precodificado. El marco muestral estuvo conformado por 917 pymes - pequeñas y medianas empresas que operan en Lima metropolitana-, y fue confeccionado con información obtenida de la Encuesta Económica INEI 2005 y a través de lista- 
dos de algunas asociaciones que agrupan a pequeñas empresas dedicadas a la confección. Quedó distribuido de la siguiente manera:

\begin{tabular}{llr}
\hline Marco muestral & \multicolumn{2}{c}{ Empresas textiles } \\
\hline Pequeñas & 761 & $83,0 \%$ \\
Medianas & 156 & $17,0 \%$ \\
Total & 917 & $100,0 \%$ \\
\hline
\end{tabular}

Para la selección de la muestra se utilizó un muestreo aleatorio sistemático a partir del listado de las medianas y pequeñas empresas que conforman el referido marco.

Con el fin de definir la categorización de las pymes entre medianas y pequeñas, se aplicó un cuestionariofiltro, de tal manera que los entrevistados cumpliesen con las siguientes características: ser fabricantes de productos textiles, tener al menos una marca propia, facturar entre 150 UIT y 850 UIT para el caso de las empresas pequeñas y mayor a 850 UIT para el caso de las empresas medianas, y realizar algún tipo de publicidad para promocionar sus productos. Con miras a evitar duplicaciones, los listados se cruzaron para dejar un listado final consolidado. Se consideró una muestra estadística de 196 pymes y se mantuvo en su composición una proporcionalidad similar a la que presenta el universo entre empresas medianas $\mathrm{y}$ pequeñas.

\begin{tabular}{lrrr}
\hline $\begin{array}{l}\text { Empresas } \\
\text { textiles }\end{array}$ & Universos & $\begin{array}{r}\text { Muestra } \\
\text { efectiva }\end{array}$ \\
\hline Medianas & 156 & $17,0 \%$ & 31 \\
Pequeñas & 761 & $83,0 \%$ & 165 \\
Total & 917 & $100.0 \%$ & 196 \\
\hline
\end{tabular}

Considerando una población finita $\mathrm{y}$ asumiendo un nivel de confianza de $95 \%(\mathrm{t}=1.96)$ y valores para $\mathrm{p}=\mathrm{q}=50 \%$ (0.5), se obtiene un margen de error de $\pm 6,21 \%$ para los resultados totales.

La validación del cuestionario se realizó a través de una prueba piloto que permitió establecer su operatividad, y el trabajo de campo se llevó a cabo del 1 al 18 de diciembre del 2006.

\section{Resultados del estudio cuantitativo}

La gran mayoría de las empresas medianas y pequeñas consideran importante la publicidad para el crecimiento de su empresa: así lo manifiesta, como promedio general, el $98 \%$ de ellas. Tanto unas como otras coinciden en que han obtenido resultados positivos de la publicidad. Primero, con un $53,7 \%$ como promedio, por haber hecho conocidas sus marcas; en segundo lugar, con un $38 \%$, por haber incrementado sus ventas; siguiendo después, entre las principales respuestas, un $16,7 \%$ que hace referencia a la ampliación de la cartera de clientes. 
En las respuestas sobre el conocimiento de los medios, son los masivos los que juegan el rol preponderante. En efecto, la televisión obtiene el $90,3 \%$ de las menciones totales, seguida por la radio con el $81,1 \%$; luego vienen los medios gráficos: diarios, revistas, y las Páginas Amarillas, entre los más destacados.

Internet obtiene un importante y singular índice de $25,8 \%$ en las menciones de las empresas medianas y $27,9 \%$ en las pequeñas, siendo las medianas las que han encontrado en este medio un gran potencial de comunicación, especialmente en el ámbito internacional.

Los volantes, folletos, letreros en el punto de venta, paneles en la vía pública, pancartas y jaladores son elementos presentes en la mente de los confeccionistas, puesto que les permiten atraer a los clientes que se encuentran cercanos a sus tiendas.

Las tarjetas de presentación, las etiquetas y las "jantas" que van incluidas en las vestimentas, sirven no solamente para informar sobre el nombre y el cargo del ejecutivo, o, como es el caso de las segundas, para poner de relieve el nombre de la marca y sus características, sino que también se convierten en vehículos para publicitar sus productos dando información adicional sobre otros aspectos relacionados con estos. Dichas formas de presentación son utilizadas por lo general por las empresas pequeñas, las cuales tratan de darles la mayor utilidad posible incluyendo en ellas, por ejemplo, un calendario anual. De esta forma, buscan una mayor permanencia del elemento publicitario en el cliente.

También es importante resaltar las menciones que las empresas medianas dan a los desfiles de moda (29\%) y a los canjes televisivos para la promoción de sus productos (13\%).

Ante la pregunta sobre los medios que utilizan para promocionar sus productos, encontramos diferencias significativas entre las empresas pequeñas y medianas. $\mathrm{Al}$ poseer las medianas mayores recursos y muchas de ellas estar abocadas a la exportación donde distribuyen gran parte de su producción, pueden en mayor medida hacer uso de medios masivos y de otros adicionales que les permiten llegar a los mercados extranjeros. Las pequeñas empresas, por su parte, disponen de recursos limitados $\mathrm{y}$, debido a ello, centran sus operaciones en el mercado nacional.

Las empresas medianas utilizan paralelamente medios BTL (below the line) y ATL (above the line). En lo que respecta a los medios BTL, mencionan desfiles de modas, presentaciones en ferias internacionales y de materiales para el punto de venta, como letreros especiales, maniquíes y jaladores, entre otros.

La televisión, a través de anuncios y canje publicitario, es el medio ATL que utiliza la mediana empresa y que la diferencia de las pequeñas. El canje lo aplican auspiciando programas que son pagados con vestimenta que utili- 
zan los conductores. En menor medida, dichas empresas hacen publicidad en diarios y revistas, siendo baja su inversión en radio porque este medio no muestra la imagen del producto. Con el fin de ampliar su mercado al ámbito internacional, el uso de internet es muy importante para ellas y es utilizado publicitariamente por el $71 \%$ de estas empresas. Igualmente, las relaciones con instituciones gubernamentales tienen una alta gravitación, ya que los convenios comerciales con otros países les favorecen para introducir sus productos a mercados del exterior.

Las empresas pequeñas apuntan principalmente a medios de muy poco presupuesto, tanto así que las tarjetas de presentación, las etiquetas y las "jantas" que van incluidas en las indumentarias y las bolsas con las que entregan la mercadería se constituyen en sus principales medios utilizados. También explotan la publicidad en el punto de venta a través de los maniquíes, volantes, letreros y jaladores para atraer a las personas que transitan cerca de las tiendas, recursos que también son utilizados por las medianas empresas. Internet solo es utilizada por $16,4 \%$ de ellas. A pesar de que su costo es bajo, aún no le dan la importancia del caso, tal vez debido a la falta de conocimiento de su alcance. Respecto a los medios masivos, utilizan el teléfono, las Páginas Amarillas y la radio.

Las empresas medianas reconocen a la televisión y a las ferias internacionales como los medios más idóneos para publicitarse; el primero lo usan en el mercado local y el segundo para introducir sus productos en el mercado internacional. Por otro lado, las empresas pequeñas, al estar enfocadas principalmente en el mercado nacional, aspiran a utilizar la televisión y en menor medida la radio, con el fin de alcanzar mayores mercados, tal como lo hacen las grandes marcas.

Mientras que las empresas medianas orientan sus mayores inversiones a la televisión $(19,4 \%)$, las relaciones con las instituciones $(16,1 \%)$, las ferias, los catálogos y las Páginas Amarillas, las pequeñas invierten más en la confección de etiquetas $(35,2 \%)$ y "jantas" (8,5\%), bolsas $(18,2 \%)$, tarjetas de presentación y también en las Páginas Amarillas.

La creatividad de los mensajes para los diferentes medios, tanto en las medianas como en las pequeñas empresas, es decidida por ellas mismas; así lo manifiesta el $64,5 \%$ y el $47,3 \%$, respectivamente. Como segunda opción, el encargo del diseño recae en una persona independiente, un free lance especializado en hacer publicidad. En último término recurren a la contratación de una agencia de publicidad (el 29\% de las medianas empresas y solo el 4,8\% de las pequeñas).

$\mathrm{Si}$ analizamos quiénes han diseñado el mensaje según el tipo de medio, observamos que la mayoría de ellos (etiquetas, tarjetas de presentación, volantes, letreros, Páginas Amarillas, folletos, pancartas, catálogos y pane- 
Principales medios en los que las pymes invierten mayores recursos económicos
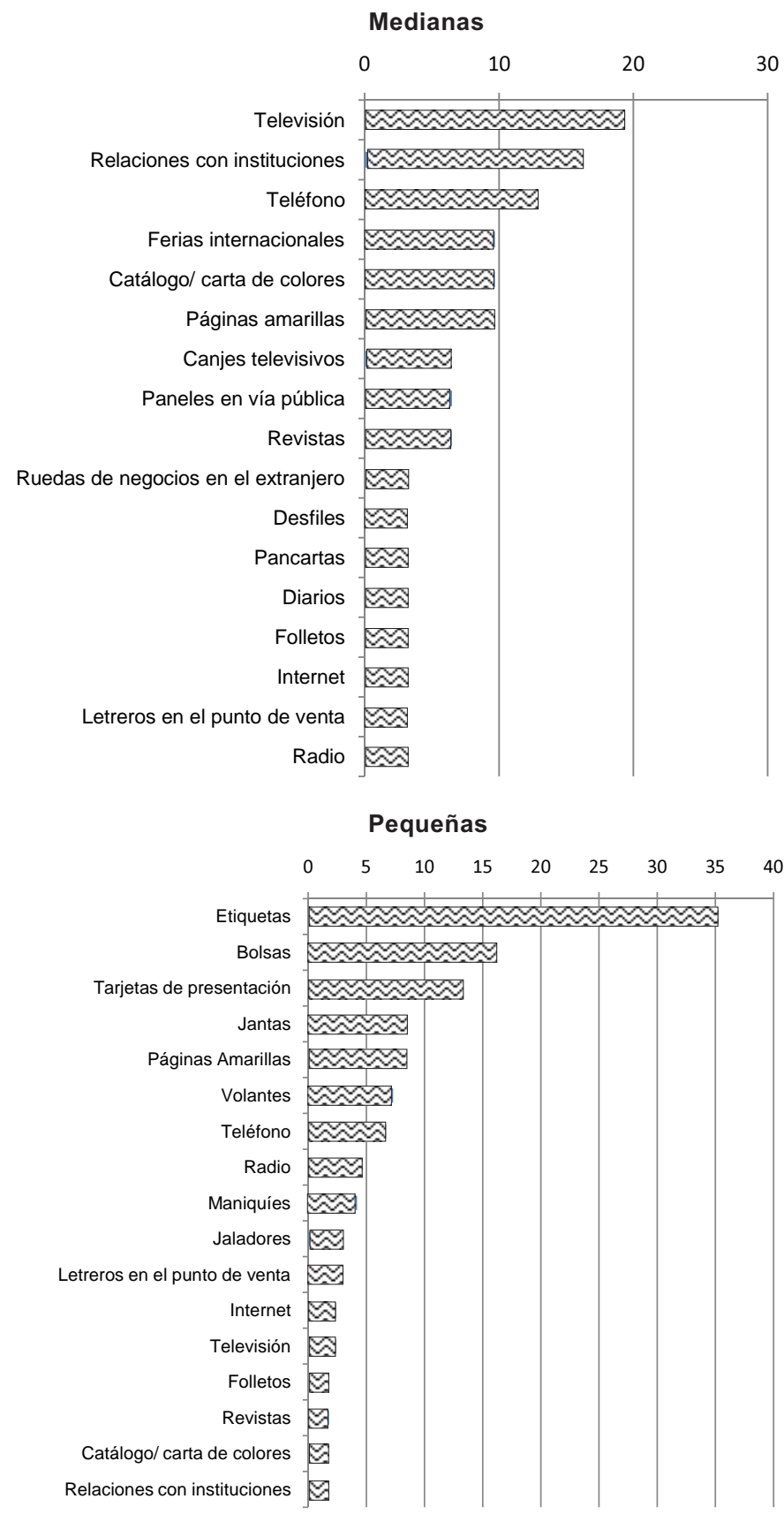

Elaboración propia. 
les) han sido realizados aproximadamente en el $50 \%$ de los casos, por las mismas empresas, encargándose el otro $50 \%$ a personas especializadas que trabajan en forma independiente. En el caso de las "jantas" y las bolsas, el $70 \%$ se le encarga a especialistas.

En cuanto a los diseños para medios como internet, desfiles de modas y ferias internacionales, prácticamente el $100 \%$ de la realización es decisión de la propia empresa.

Para el caso del manejo de los contenidos publicitarios en los medios masivos, como la televisión y los diarios, las empresas medianas encargan esta responsabilidad a personas especializadas.

Si bien es cierto que las empresas de confección en general reconocen la publicidad como un elemento importante en la comercialización de sus productos, demuestran improvisación y poco manejo profesional en la gestión de la estrategia publicitaria. Las empresas medianas aún conservan las prácticas en esta área estratégica como cuando eran pequeñas, $y$ buscan el máximo ahorro de recursos antes de maximizar los efectos que puede darles la publicidad. Se prioriza un manejo coyuntural en el desarrollo de las campañas y no una planificación estratégica de la promoción del producto.

Cuando se les pregunta sobre el presupuesto publicitario, el $74,2 \%$ de las medianas y el $52,7 \%$ de las pequeñas lo definen con anticipación, destinando a la publicidad, en ambos casos, entre el $1 \%$ y el $5 \%$ del porcentaje de sus ventas.

El $77,6 \%$ de medianas y pequeñas empresas tiene como objetivo incrementar sus ventas con sus inversiones publicitarias y el 35,7\% de ellas desea lograr un mayor conocimiento de la marca.

El nombre de la marca de los productos ha partido de la decisión del dueño de la empresa; en ningún caso se ha aplicado una investigación que involucre al consumidor.

Respecto a las épocas del año en que realizan publicidad, el $71 \%$ de las empresas medianas manifiesta que lo hace durante todo el año; de esta manera, puede mantener el índice de recordación de la marca, mientras que solamente el $38,2 \%$ de las pequeñas realiza algún tipo de publicidad anual continua, y en fechas especiales, como el Día de la Madre, Fiestas Patrias, el Día del Padre, Navidad, etcétera, refuerzan su oferta publicitaria.

Tanto las medianas como las pequeñas empresas muestran interés en publicitar en televisión, así lo manifiesta el 17,3\% de ellas. Del mismo modo, muestran interés en crear páginas web, reconociendo el potencial de este medio. Las medianas, por su orientación al mercado exterior, prefieren invertir en catálogos, y las pequeñas están proyectando realizar más publicidad en radio, como una forma económica de alcanzar un mayor mercado. 
El 54,8\% de las empresas medianas y el $21,8 \%$ de las pequeñas, han recibido algún tipo de capacitación en el manejo publicitario. Prompyme es la institución que más se ha preocupado por realizar esta labor, especialmente con las pequeñas.

La gran mayoría de las empresas $(87,2 \%)$ está interesada en recibir algún curso sobre estrategias publicitarias. Al parecer, ateniéndose a los cursos impartidos por instituciones como Prompyme, las capacitaciones han estado orientadas principalmente a la gestión empresarial y a la exportación, ocupando la promoción un aspecto secundario en el currículo de los cursos.

\section{Conclusiones generales}

Prácticamente la totalidad de las pymes considera la publicidad como un elemento importante para el crecimiento de sus empresas, puesto que les ha permitido la difusión de sus marcas, incrementar sus ventas y ampliar su cartera de clientes.

Respecto al volumen de inversión en publicidad, el rubro de vestimenta es aún incipiente en la utilización de los medios masivos publicitarios.

Las marcas con mayor inversión utilizan generalmente la televisión como medio eje, y los otros medios en forma complementaria.

Las pequeñas empresas emplean medios de menor cobertura, dado que aún están en una etapa de limitada producción y sus productos tienen poca distribución. Consideran, por ello, que la utilización de medios masivos puede ser contraproducente para sus intereses económicos. Ello no es óbice para que algunas empresas recurran eventualmente a los medios masivos (diarios, revistas y televisión), hecho que refleja su aspiración a publicitar en medios de mayor cobertura.

Los medios masivos encabezan el top of mind en el caso de recordación espontánea, especialmente la televisión y la radio; sin embargo, como ya se ha dicho, no son los medios más utilizados por las pymes.

En muchos casos, las empresas medianas orientan su publicidad a los mercados nacional e internacional. En el ámbito nacional hacen uso de medios masivos, como diarios, revistas e internet, reservando otro material publicitario para el punto de venta. En el ámbito internacional le dan mucha importancia a las ferias internacionales, a los catálogos y a la relación con las instituciones que les permitan el nexo con los mercados del exterior.

Las pequeñas empresas, por lo general, dedican sus limitados recursos económicos a la publicidad en medios de bajo presupuesto o below the line, como tarjetas de presentación, bolsas, "jantas", maniquíes, volantes, jaladores, etcétera. Los medios masivos son utilizados en menor medida, destacando los de bajo costo como la radio, la internet y las Páginas Amarillas. 
Las empresas medianas emplean la televisión para dirigirse al mercado interno y las ferias internacionales para el mercado externo, mientras que las pequeñas aspiran a usar la televisión como medio ideal para alcanzar mayor cobertura en el mercado local. También negocian con los medios masivos mediante canjes publicitarios aplicando la estrategia de product placement, que consiste en obtener presencia o menciones publicitarias dentro de programas de televisión o radio.

En el caso de las pequeñas empresas, los propietarios o encargados participan en la creación del mensaje publicitario; en las medianas este trabajo se delega a personas especializadas o a agencias de publicidad.

Con relación a la recordación de sus marcas, las empresas medianas se preocupan por mantenerla mediante algún tipo de publicidad a lo largo del año, mientras que las pequeñas solo realizan campañas estacionales.

La mayoría de las pymes dedican entre $1 \%$ y $5 \%$ de sus ventas a la inversión publicitaria.

En cuanto a la capacitación de su personal, las empresas medianas en mayor proporción que las pequeñas manifiestan haber recibido algún tipo de capacitación en el manejo publicitario.

La gran mayoría de las pymes desea recibir algún curso sobre estrategias publicitarias. Al parecer, la capacitación recibida por algunas de ellas ha sido más orientada a la gestión empresarial y la promoción se ha tocado tan solo de manera tangencial.

\section{Bibliografía}

ANDRIANI, Carlos; BiAsCA, Rodolfo y Mauricio Rodríguez (2003). Un nuevo sistema de gestión para lograr pymes de clase mundial. México: Norma.

Arens, William (2000). Publicidad. México: McGraw-Hill.

BASSAT, Luis (1999). El libro rojo de la publicidad. Madrid: Espasa Calpe, S.A.

Kleppner's, Otto 1988. Publicidad. México: Prentice Hall Hispanoamericana.

KotLer, Philip y G. Amstrong (1998). Fundamentos de mercadotecnia. México: Prentice Hall.

Ley 27268, Ley General de la Pequeña y Microempresa, del 16 de mayo del 2002. <http://www.produce. gob.pe/industria/normatividad/m edioambiente/leyes/Ley27268.php >. [Consulta: 31 de marzo del 2006.]

Media Check [2005]. Estudios de Monitoreo de avisos publicitarios. Lima: enero-diciembre.

StANTON, William; BRUCE, J. Walker y Michael J. ETzel [2000]. Fundamentos de marketing. México: McGrawHill. 